\title{
Discours
}

Revue de linguistique, psycholinguistique et

informatique. A journal of linguistics, psycholinguistics and computational linguistics

$11 \mid 2012$

Varia

\section{How Different Information Sources Interact in the Interpretation of Interleaved Discourse: The Case of Two-Step Enumerative Structures}

Marianne Vergez-Couret, Laurent Prévot and Myriam Bras

(2) OpenEdition

Journals

Electronic version

URL: http://journals.openedition.org/discours/8743

DOI: $10.4000 /$ discours. 8743

ISSN: 1963-1723

Publisher:

Laboratoire LATTICE, Presses universitaires de Caen

Electronic reference

Marianne Vergez-Couret, Laurent Prévot and Myriam Bras, « How Different Information Sources

Interact in the Interpretation of Interleaved Discourse: The Case of Two-Step Enumerative

Structures », Discours [Online], 11 | 2012, Online since 23 December 2012, connection on 02 May 2019

URL : http://journals.openedition.org/discours/8743; DOI : 10.4000/discours.8743

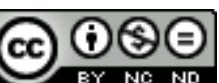

Discours est mis à disposition selon les termes de la licence Creative Commons Attribution - Pas d'Utilisation Commerciale - Pas de Modification 4.0 International. 

Revue de linguistique, psycholinguistique et informatique

\title{
How Different Information Sources Interact in the Interpretation of Interleaved Discourse: The Case of Two-Step Enumerative Structures
}

\author{
Marianne Vergez-Couret \\ UMR 5263 CLLE-ERSS \\ Université de Toulouse \\ Laurent Prévot \\ UMR 7309 LPL \\ Université Aix-Marseille
}

Myriam Bras

UMR 5263 CLLE-ERSS

Université de Toulouse 



\title{
How Different Information Sources Interact in the Interpretation of Interleaved Discourse: The Case of Two-Step Enumerative Structures
}

\author{
Marianne Vergez-Couret \\ UMR 5263 CLLE-ERSS \\ Université de Toulouse \\ Laurent Prévot \\ UMR 7309 LPL \\ Université Aix-Marseille \\ Myriam Bras \\ UMR 5263 CLLE-ERSS \\ Université de Toulouse
}

\begin{abstract}
Little attention has been devoted to interleaved discourse structures despite the challenges they offer to discourse coherence studies. Interleaved structures occur frequently if several dimensions of discourse coherence (semantic, intentional, textual, etc.) are considered simultaneously on relatively large texts. Two-step enumerative structures, a kind of interleaved structure, are enumerative structures in which the items are further developed in an enumerative fashion. We propose in this paper a treatment of the semantic and textual dimensions of such structures. We also propose some generalizations for the treatment of interleaved structures.
\end{abstract}

Keywords: Segmented Discourse Representation Theory, discourse structure, Enumeration, interleaved structures, two-step enumerative structures

Les structures discursives croisées ont très peu attiré l'attention des chercheurs jusqu'à maintenant. Pourtant leur analyse soulève des questions qui sont de véritables défis pour les théories de la cohérence du discours. Les structures croisées sont fréquemment introduites par l'analyse conjointe des différentes dimensions de la cohérence discursive (sémantique, intentionnelle, textuelle...) sur des empans textuels significatifs. Les structures énumératives à deux temps, une sorte de structure croisée, sont des structures énumératives dans lesquelles les items sont eux-mêmes développés selon un processus énumératif. Nous proposons ici un traitement des dimensions sémantique et textuelle de ces structures. Nous avançons aussi des pistes pour généraliser nos traitements à un traitement des structures croisées dans leur ensemble.

Mots clés: Segmented Discourse Representation Theory, structure du discours, Énumération, structure croisée, structure énumérative à deux temps

\section{Introduction}

We take in this paper a bottom-up and relational approach to discourse structure. Discourse is modeled as a hierarchical structure relying on coherence links between discourse units. These links are captured using the notion of discourse relations 
(Mann \& Thompson, 1987; Asher \& Lascarides, 2003; Wolf \& Gibson, 2005). The hierarchical nature of the structure allows for the definition of a Right Frontier Constraint (hereafter RFC), a principle constraining the accessible sites for continuation as well as the material available for anaphora. The RFC is grounded on the assumption that one can distinguish two types of discourse relations: subordinating relations which introduce some kind of hierarchy between the discourse segments they relate, and coordinating relations which correspond to some kind of discourse progression between discourse segments having a similar discourse function. This distinction results in a tree-like structure for discourse organization. Figure $\mathrm{I}$ is an example of hierarchical structure in the Segmented Discourse Representation Theory (SDRT) (Asher \& Lascarides, 2003) where subordinating relations may be, for instance, Elaboration or Explanation and coordinating relations may be, for instance, Narration or Continuation:

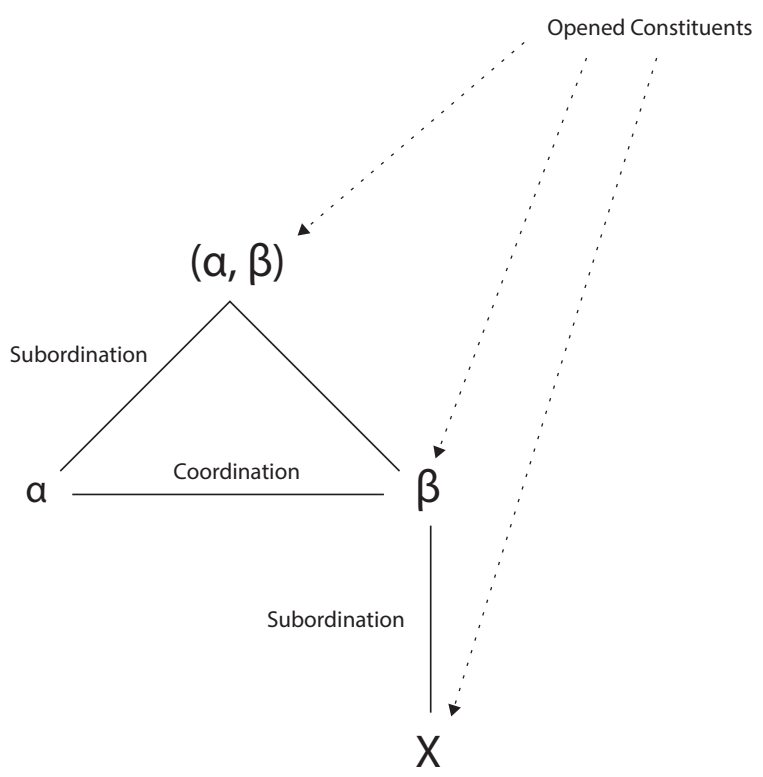

Figure 1. The Right Frontier

RFC requires that new discourse constituents cannot be integrated anywhere in the tree representing preceding discourse but only in a well-defined area situated at the Right Frontier of the tree (see Figure I). The constituents situated in this area are said to be open for attachment while all the others are said to be closed (Polanyi, 1988; Asher \& Lascarides, 2003). Constituents that are targets of a coordinating relation are not available for further attachment (see $\alpha$ in Figure I).

However some discourse structures that have been described in the literature as crossed dependencies (Wolf \& Gibson, 2005) or interleaved structures (Asher, 1993), like [I], described for example in Asher (1993: 343), seem to constitute a problem for the standard version of this principle. 
[I] There are two houses you might be interested in: House A is in Palo Alto, House B in Portola Valley. Both were built in I950, and both have 3 bedrooms. House A has 2 baths, and B, 4. House A also has a kidney-shaped pool. House A is on a quarter acre, with a lovely garden, while House B is on 4 acres of steep wooded slope, with a view of the mountains. The owner of House B is asking $\$ 425 \mathrm{~K}$. The owner of house $\mathrm{A}$ is asking $\$ 600 \mathrm{~K}$.

(Asher, 1993: 345)

The structures, illustrated in [I], have been described as allowing discourse attachment to closed-off constituents contrarily to RFC predictions.

In this paper, we consider two-step enumerative structures as an entry point for more general interleaved constructions. We evaluate the ability of SDRT (Asher, I993; Asher \& Lascarides, 2003) to account for these structures. Two-step enumerative structures are a special kind of so-called enumerative structure. Enumerative structures were brought to the fore by top-down approaches to discourse which compare visual surface structures with discourse semantic structures and assume a functional equivalence between them (Luc et al., 1999; Luc et al., 2000; Ho-Dac, Péry-Woodley \& Tanguy, 20ı; Ho-Dac et al., 20I2). They are textual structures composed of an introducing sentence (or trigger) and of a list of several co-items forming an enumeration. They are signaled by linguistic and/or visual means. The recognition of these structures as such guides the interpretation of discourse. A two-step enumerative structure is composed of two simple enumerative structures (SEI, called first step and $\mathrm{SE}_{2}$, called second step), where the items of SEI are further developed by the items of SE2 (Porhiel, 2007). [2] is an example of these structures that we propose to analyze in this paper.

[2] (a) Deux fois, Nil crut sombrer dans le gouffre: (b) d'abord chez Vrin, (c) où il feuilletait des livres avec Anne-Geneviève, (d) quand Laure y entra inopinément; (e) ensuite à la bibliothèque de Beaubourg, (f) où il était assis en face de Laure, (g) et où Anne-Geneviève apparut soudain. (h) Chez Vrin, (i) dès qu'il avait vu Laure, (j) Nil s'était lâchement jeté dans l'arrière-boutique, (k) pour n'en sortir (l) qu'après s'être assuré que son amante numéro deux ne se trouvait plus dans la librairie. (m) À Beaubourg, (n) Anne-Geneviève n'était, Dieu merci, restée qu'un instant [...], (o) et Laure n'avait même pas levé le nez de ses cahiers.

(a) Twice, Nil thought that he was in big trouble: (b) first at Vrin, (c) where he was browsing books with Anne-Geneviève, (d) when Laure entered unexpectedly; (e) then at the Beaubourg library, (f) where be was seated facing Laure, (g) and where AnneGeneviève suddenly appeared. (b) At Vrin, (i) as soon as be had seen Laure, (j) Nil ignominiously escaped to the backroom, $(k)$ and only reappeared (l) after checking that bis lover number two had left the bookstore. (m) At Beaubourg, (n) Anne-Geneviève, thank God, only stayed for a second [...] (o) and Laure did not look up from ber books. (Gabriel Matzneff, Ivre du vin perdu, Paris, Gallimard [Folio; 1503], 1983, p. 331; we translate into English) 
Here a second step (h-o) corresponds to $\mathrm{SE}_{2}$ and follows the first step (SEI) composed of the trigger or introducing sentence (a) and the first enumeration (b-g).

These structures have received little attention from bottom-up discourse theories that focus generally on linguistic markers and linguistic content rather than textual level information. However, discourse relations are often classified according to the kind of information involved in their recognition, i.e., semantic content vs. textual shape or intention recognition (Sanders, Spooren \& Noordman, 1992; Bateman \& Rondhuis, 1997; Degand, 1998; Knott, Sanders \& Oberlander, 2002). SDRT introduces a distinction between content-level relations (Narration, Elaboration, Result, etc.) and text structuring relations (Parallel, Contrast).

Bras, Prévot and Vergez-Couret (2008) and Vergez-Couret et al. (20II) proposed to take enumerative structures into account when building discourse representations, thus attempting to combine a bottom-up approach to discourse in SDRT with insights from top-down approaches. In this paper, we will extend our analysis to two-step enumerative structures that challenge the attachment principle, in order to better understand the interaction between different discourse levels, here the content level and the textual level.

The paper is organized as follows. We will start by presenting the theoretical background of the study, the SDRT model (Section 2). This is followed by a description of enumerative structures and two-step enumerative structures (Section 3) and the challenges the latter offer to discourse theories (Section 4). Section 5 will present the general idea of our proposal. Then we will take a closer look at the semantic aspect of two-step enumerative structures by analyzing in detail a complex example (Section 6). We will also compare our account to a related proposal on interleaved structures (Section 7). Finally, in Section 8, we will draw some prospective generalizations from the preceding sections.

\section{Theoretical background}

\subsection{SDRT}

SDRT (Asher, 1993; Asher \& Lascarides, 2003) is a formal theory of discourse. It is an extension of Discourse Representation Theory (Kamp \& Reyle, 1993) to which it adds the crucial notion of discourse structure by taking discourse relations (Narration, Elaboration, Parallel...) into account.

SDRT aims at constructing Segmented Discourse Representation Structure (SDRS), reflecting discourse interpretation. The basic constituents (or Elementary Discourse Units - EDU) of the SDRS are labeled Discourse Representation Structures (DRS), describing the propositional content of EDUs. EDUs can be grouped under complex constituents that are also labeled.

Greek letters $(\pi, \alpha, \beta \ldots)$ are used to represent these labeled (elementary or complex) constituents. $\mathrm{K}_{\alpha}$ is used to represent the constituent with the label $\alpha$, 
and $\mathrm{e}_{\alpha}, \mathrm{e}_{\beta} \ldots$ are used to represent the main eventuality described in the constituents (Asher, 1993).

The construction of an SDRS is achieved segment by segment, by adding the label of the segment which is processed to the existing structure (resulting from the treatment of the preceding segments). The construction is done in three main steps. First, a DRS is built compositionally. Then, the attachment point of the new label is determined. As an SDRS is a structured object, this new label may be attached to different locations of the structure. The RFC determines these available sites. For each available attachment point, the possible discourse relations are considered on the basis of various information sources (see 2.2 for a presentation of the information sources and 2.3 for a presentation of existing rules to infer discourse relations). Once the attachment point and one or more discourse relation(s) have been determined, the last step consists in the update of the whole SDRS: the update of the structure with the construction of complex and potential implicit constituents (discourse topics) as well as the update of the semantic content of each DRS through the calculation of the semantic effects of the relations and the resolution of various semantic underspecifications resolved thanks to the precise determination of the discourse context ${ }^{1}$.

\subsection{Information sources and discourse coherence}

Semantic information sources (temporal, causal or logical discourse markers, lexical and grammatical information, syntactic constructions, and world knowledge) are brought together for inferring content discourse relations. Other information sources (syntactic parallelism in the constituents, textual markers...) may be used for inferring textual discourse relations but have received little attention within semantic-oriented bottom-up approaches. As far as discourse markers are concerned, there are no clear distinctions between lexical and textual markers; they may actually play a role simultaneously at the content and the textual level.

For computational as well as cognitive plausibility (see Asher \& Lascarides [2003] for a discussion on this point) the language and the logic for inferring discourse relations (glue logic language or logic of information packaging) are kept distincts from the ones used to express the semantic effect of the relations (logic of information content).

\subsection{Inferring discourse relations}

To begin, let's see how to read the axioms from the Glue Logic to infer discourse relations. They contain the following notations:

- $\mathrm{R}(\alpha, \beta, \lambda)$ signals that the discourse relation $\mathrm{R}$ holds between discourse constituents $\alpha$ and $\beta$ in the dominating constituent $\lambda$;

1. For a more detailed presentation of SDRT, the reader may refer to Asher, Prévot and Vieu (2007) in the first issue of this journal. 
- [text $](\alpha)$ means that the discourse constituent $\alpha$ includes an element "text";

- predicate $(\lambda, \alpha, \beta)$ means that a specific predicate is inferred between the type of eventuality described in $\alpha$ and $\beta$ relying on lexical semantics and world knowledge;

$-\rightarrow$ stands for strong inference;

$->$ stands for default inference that can be overruled in the event of more precise information and the corresponding rule (Asher \& Moreau, I99I).

Let us start with frequently studied content discourse relations that we will need later in the treatment of our main examples: Elaboration, Continuation, Narration, and Background.

\subsubsection{Elaboration and Continuation}

Elaboration is a subordinating relation. One way to infer Elaboration involves the Subtype $_{D}$ predicate. Subtype $e_{D}$ holds when the type of the second eventuality (state or event) is a subtype of the first one, based on lexical semantics or world knowledge. When Subtype $e_{D}$ holds, Elaboration can be inferred.

- Axiom Infer_Elaboration_Subtype

$$
\left(?(\alpha, \beta, \lambda) \wedge \operatorname{Top}(\sigma, \alpha) \wedge \operatorname{Subtype}_{\mathrm{D}}(\sigma, \beta, \alpha)\right)>\text { Elaboration }(\alpha, \beta, \lambda)
$$

This is the case for Example [3] from Kamp and Rohrer (1983):

[3] (a) L'été de cette année-là vit plusieurs changements dans la vie de nos héros.

(b) François épousa Adèle, (c) Jean-Louis partit pour le Brésil et (d) Paul s'acheta une maison à la campagne.

(a) In the summer of that year, many changes took place in our heroes' lives. (b) François married Adèle, (c) Jean-Louis left for Brazil and (d) Paul bought a country bouse.

(Kamp \& Rohrer, 1983: 26r; we translate into English)

We ( $>$ ) infer non-monotonically ${ }^{2}$ that the type of the second event "épouser Adèle" (marry Adèle) is a subtype of the first one "voir plusieurs changements dans la vie de nos héros" (many changes took place in our heroes' lives) thanks to world knowledge. The same inferences can be drawn for the types of "partir pour le Brésil" (leave for Brazil) and "s'acheter une maison" (buy a bouse) which are subtypes of the event "voir plusieurs changements dans la vie de nos héros". This leads to the inference of Elaboration $\left(\pi_{a}, \pi_{b}\right)$, Elaboration $\left(\pi_{a}, \pi_{c}\right)$, Elaboration $\left(\pi_{a}, \pi_{d}\right)$.

Elaboration has a semantic effect on discourse content. It implies that the main eventuality of each elaborating constituent is part of the main eventuality of the elaborated clause (see Aurnague and Vieu [1993] for a definition of the Part-of relation). A temporal inclusion between them follows from this effect.

2. Non-monotonically means that the inference can be cancelled if other monotonic inferences are established. 


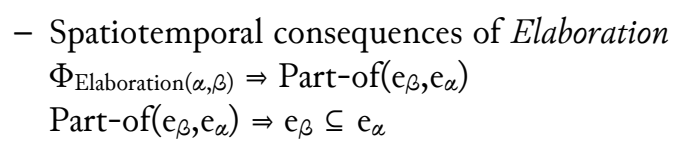

The axiom of Distributivity says that if we have inferred Elaboration $\left(\pi_{a}, \pi_{b}, \pi_{0}\right)$ and Elaboration $\left(\pi_{a}, \pi_{c}, \pi_{0}\right)$, as in [3], we may attach $\pi_{c}$ to $\pi_{b}$. The discourse relation that holds is Continuation, a coordinating relation with no temporal consequences. The same reasoning goes for the attachment of $\pi_{c}$ and $\pi_{d}$ by Continuation. The following axiom from Prévot (2004: 60-70) states this explicitly.

- Axiom Infer_Continuation $(?(\beta, \delta, \lambda) \wedge$ Elaboration $(\alpha, \beta, \lambda) \wedge$ Elaboration $(\alpha, \delta, \lambda)) \rightarrow$ Continuation $(\beta, \delta, \lambda)$

Finally, the Complex Constituents Rule will lead us to build the complex constituent $\pi_{A}$ from $\pi_{b}, \pi_{c}, \pi_{d}$ which as a whole elaborates $\pi_{a}$ : Elaboration $\left(\pi_{a}, \pi_{A}, \pi_{0}\right)$. The discourse structure for [3] is given in Figure 2.

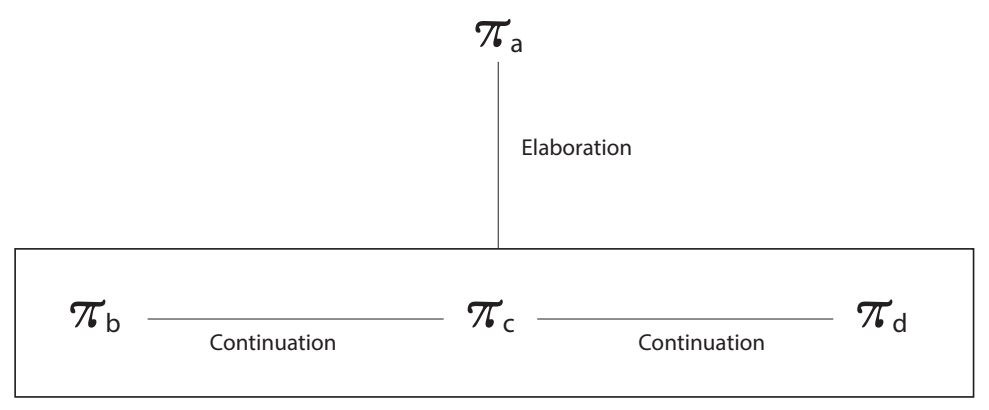

Figure 2. Discourse structure for [3]

\subsubsection{Narration}

Narration is a coordinating relation. A new constituent may be attached to the context via Narration if the Occasion predicate can be inferred between the types of the eventualities involved (see [4]). The Occasion predicate encodes the knowledge that the type of the second event may lead to the first one by relying on lexical semantics and shared knowledge.

- Axiom Infer_Narration_Occasion $\operatorname{Narration}(?(\alpha, \beta, \lambda) \wedge \operatorname{Occasion}(\alpha, \beta))>\operatorname{Narration}(\alpha, \beta, \lambda)$

For [4], relying on a script stating that "after a fall, someone may help", Occasion can be inferred.

[4] (a) Max fell. (b) John helped him up.

(Asher \& Lascarides, 2003: 20I)

Narration can also be inferred if the constituent is introduced by a certain kind of lexical marker such as and then, see [5]: 
[5] (a) Kim watched TV. (b) And then she went out.

(Asher \& Lascarides, 2003: 202)

- Axiom Infer_Narration_and then $(?(\alpha, \beta, \lambda) \wedge$ [and then $](\beta)) \rightarrow \operatorname{Narration}(\alpha, \beta, \lambda)$

The semantic effect of Narration on discourse content is given below.

- Temporal consequences of Narration

$\varnothing_{\text {Narration }} \Rightarrow \mathrm{e}_{\alpha}<\mathrm{t}_{\mathrm{t}} \mathrm{e}_{\beta}$

It implies that the main eventuality of $\alpha$ precedes the main eventuality of $\beta$.

\subsubsection{Background}

Background is a subordinating relation. It relates two segments where one state describes a background and one event describes the foreground, as in [6].

[6] Max entered the room. It was pitch dark.

Background is inferred when both constituents describe respectively a state and an event.

- Axiom Infer_Background

$$
(?(\alpha, \beta, \lambda) \wedge \operatorname{event}(\alpha) \wedge \operatorname{state}(\beta))>\operatorname{Background}(\alpha, \beta, \lambda)
$$

Cases where the background is introduced before the foreground, as in [7], were studied by Asher, Prévot and Vieu (2007).

[7] It was pitch dark. Max entered the room.

They proposed a homogenous treatment of the two Background relations presented here, Background backward in [6], and Background forward in [7]. The Background backward introduces two constituents linked by the Background relation (see “Axiom Infer_Background”). Backgroundforward introduces a more complex structure with an additional framing topic constituent linked to the background by a Background relation and to the foreground by an Elaboration ${ }^{3}$.

The temporal constraints given by Background are as follows.

- Temporal consequences of Background

$\varnothing_{\text {Background }} \Rightarrow \mathrm{e}_{\alpha} \subseteq_{\mathrm{t}} \mathrm{e}_{\beta}$

Flashback, Consequence and Alternation are less widely studied content-level discourse relations but as we will need them in the following section, a brief description and illustration is given here.

3. Cf. Asher, Prévot and Vieu (2007) for a more detailed description of this relation. 


\subsubsection{Flashback}

Flashback is a subordinating relation. This relation was introduced in Bras and Asher (1994) for cases of look back in narrative texts. Flasbback is inferred when a segment introduces an eventuality which corresponds to a look back in the narration. The inference of this relation relies on grammatical cues, such as the pluperfect (French plus-que-parfait), lexical markers such as after, lexical semantics and world knowledge.

[8] Peter went back home. Thieves had stolen his car.

The semantic effect of Flashback on discourse content is given below.

- Temporal consequences of Flasbback

$\varnothing_{\text {Flashback }} \Rightarrow \mathrm{e}_{\beta}<\mathrm{t} \mathrm{e}_{\alpha}$

It implies that the main eventuality of $\beta$ precedes the main eventuality of $\alpha$.

\subsubsection{Consequence}

Consequence is a coordinating relation. It holds between two constituents when one of them describes the antecedent and the other one the consequent of an implication.

[9] If there is a bathroom, then it is in a funny place.

\subsubsection{Alternation}

Alternation belongs to coordinating relations. It captures the case when a logical disjunction holds between the two constituents.

[Io] Either there is no bathroom, or it is in a funny place.

Finally Parallel and Enumeration belong to the group of text-level relations.

\subsubsection{Parallel}

Parallel does not have a clear subordinating or coordinating nature. Most of the time, it follows the nature of a co-occurring content-level relation. The inference of Parallel relies on the syntactic isomorphism of the constituents it relates (Asher, Hardt \& Busquets, 200I).

[II] John speaks French. Bill speaks German.

\subsubsection{Enumeration}

The Enumeration relation was introduced in Bras (2007) and Bras, Prévot and Vergez-Couret (2008) to handle classical enumerative structures. Its inference relies on surface markers given by enumerative structures.

Enumerative structures are textual structures such as the one illustrated in Example [12]: 
[I2] (a) L'hygiène dentaire [...] se fonde sur plusieurs éléments. (b) D'abord, il importe d'assurer un bon nettoyage des dents. (c) Puis il faut savoir faire appel au dentiste dès que l'on constate quelque chose d'anormal.

(a) Dental bealth [...] is based on several elements. (b) First, it is important to brush one's teeth properly. (c) Then it is necessary to call the dentist as soon as something wrong is noticed.

(Bras, 2007: 93; we translate into English)

They are composed of an introducing sentence or trigger - here (a) - and of several co-items forming a list called enumeration (here two items: (b) and (c)) (Luc et al., 1999; Luc et al., 2000). Triggers and co-items are generally characterized by a combination of typographic and linguistic markers. In Example [I2], they are marked by linguistic clues such as a quantified noun phrase in the trigger called prospect NP ("plusieurs éléments", several elements) and specific co-item markers introducing each item ("d'abord", first; "puis", then).

Co-items $\left(\pi_{\mathrm{b}}, \pi_{\mathrm{c}}\right)$ together introduce a complex constituent $(\pi)$ which is attached to the trigger $\left(\pi_{\mathrm{a}}\right)$ by the Enumeration relation. A coordinating relation (by default Continuation) is inferred between the co-items (see Figure 3).

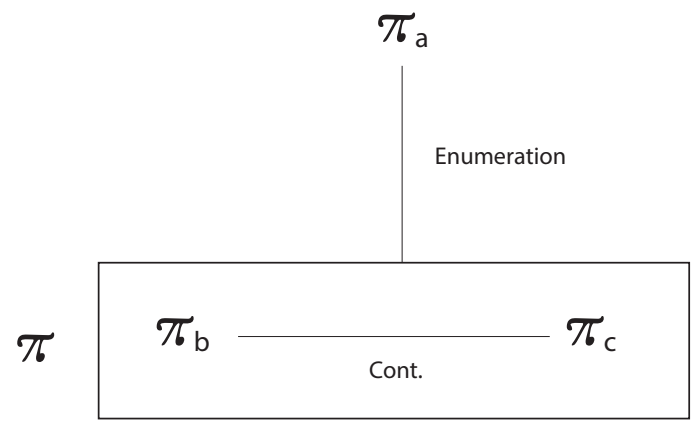

Figure 3. Discourse structure for a classical enumerative structure such as [12]

The axioms from the Glue Logic for inferring Enumeration are given in the following rules "Axiom Infer_Enumeration" and "Axiom Infer_Enumeration_OIM" (Bras, Prévot \& Vergez-Couret, 2008).

- Axiom Infer_Enumeration $(?(\alpha, \beta, \lambda) \wedge \operatorname{Trigger}(\alpha) \wedge[\mathrm{FIM}](\beta))>\operatorname{Enumeration}(\alpha, \beta, \lambda)$

This axiom states that when considering the attachment of a constituent featuring a First Item Marker (FIM) to a trigger constituent, the relation is by default an Enumeration.

- Axiom Infer_Enumeration_OIM $(?(\beta, \gamma, \lambda) \wedge \exists \alpha$ Enumeration $(\alpha, \beta, \lambda) \wedge \operatorname{OIM}(\gamma))>($ Enumeration $(\alpha, \gamma, \lambda) \wedge$ $\operatorname{item}(\gamma) \wedge$ Continuation $(\beta, \gamma, \lambda))$ 
When considering the attachment of a constituent featuring a FIM, such as "d'abord" (first), "premièrement" (firstly), to another constituent by a relation, this relation will be, by default, a topic subordinating relation $(\Downarrow)$ and we will expect another constituent, which has to be an item of the enumeration, to be attached to the currently considered constituent through a coordinating relation.

We propose in this paper to extend this proposal for enumerative structures to treat two-step enumerative structures.

\section{Two-step enumerative structures}

The example of a two-step enumerative structure from the introduction is repeated here:

[2] (a) [Deux fois, Nil crut sombrer dans le gouffre:] [(b) d'abord chez Vrin, (c) où il feuilletait des livres avec Anne-Geneviève, (d) quand Laure y entra inopinément]; [(e) ensuite à la bibliothèque de Beaubourg, (f) où il était assis en face de Laure, (g) et où Anne-Geneviève apparut soudain.] [(h) Chez Vrin, (i) dès qu'il avait vu Laure, (j) Nil s'était lâchement jeté dans l'arrière-boutique, (k) pour n'en sortir (l) qu'après s'être assuré que son amante numéro deux ne se trouvait plus dans la librairie.] [(m) À Beaubourg, (n) Anne-Geneviève n'était, Dieu merci, restée qu'un instant [...], (o) et Laure n'avait même pas levé le nez de ses cahiers.]

[(a) Twice, Nil thought that he was in big trouble:] [(b) First at Vrin, (c) where he was browsing books with Anne-Geneviève, (d) when Laure entered unexpectedly;] [(e) then at the Beaubourg library, (f) where he was seated facing Laure, (g) and where AnneGeneviève suddenly appeared.] [(b) At Vrin, (i) as soon as he had seen Laure, (j) Nil ignominiously escaped to the backroom, ( $k$ ) and only reappeared (l) after checking that bis lover number two bad left the bookstore.] [(m) At Beaubourg, (n) Anne-Geneviève, thank God, only stayed for a second [...] (o) and Laure did not look up from ber books.]

In [2], trigger and co-items are characterized by a combination of typographic (“:”) and linguistic markers: "deux fois” (twice) for the trigger, "d'abord” (first) and "ensuite" (then) for the co-items in (h-o). The co-items in the second step are not introduced by such specific item markers but by anteposed spatial locating adverbials "Chez Vrin" and "À Beaubourg". The discourse role of these locating adverbials in

This axiom states that when considering the attachment of a constituent featuring an Other Item Marker (OIM), such as "ensuite" (then), "deuxièmement" (secondly), etc. to another constituent which is an item of an enumeration, then by default, the new constituent is another item of the enumeration and continues the preceding item.

These two axioms are supplemented by the following one which states the discourse contribution of FIM.

$$
\begin{aligned}
& \text { - Axiom Infer_Subord_Coord_FIM } \\
& \quad(?(\alpha, \beta, \lambda) \wedge[\mathrm{FIM}](\beta))>\Downarrow(\alpha, \beta, \lambda) \wedge \exists \gamma \exists \mathrm{R} \in \operatorname{Coord} \mathrm{R}(\beta, \gamma, \lambda) \wedge \operatorname{item}(\gamma)
\end{aligned}
$$


initial position has been described by Charolles (2005) as introducing a discourse frame including all the segments in the scope of the locating adverbial, i.e., all the segments describing an eventuality to be located by the adverbial. An SDRT account of the frame introducers' structuring role is given in Vieu et al. (2005). In $[2]$ for instance, $(h)$ dominates $(i-1)$ and $(m)$ dominates (n-o). If we go back to the first step enumeration $(\mathrm{b}-\mathrm{g})$, we can observe that each item is structured by its item marker in combination with the locating adverbial ("d'abord chez Vrin", "ensuite à Beaubourg"). These two expressions are considered to play the same kind of framing role as the spatial locating adverbial of the second step. As far as the semantic content is concerned, segments $(\mathrm{h})$ and $(\mathrm{m})$ recall segments $(\mathrm{b})$ and (e). It is precisely this recall of the co-items in the first step that helps interpreters to represent the second step of the whole enumerative structure.

In this example, the two steps tell the reader two cross-cutting stories. In the Vrin story, Nil is with Anne-Geneviève when Laure appears in the first step. And as soon as he sees her, he escapes to the backroom in the second step. In the Beaubourg story, Nil is with Laure when Anne-Geneviève appears in the first step. But the two lovers don't see each other in the second step. So, on two occasions Nil gets into trouble, but fortunately for him his lovers do not recognize each other.

Similar examples, such as [I3], have been analyzed in Schnedecker (2006). In Example $\left[\mathrm{I}_{3}\right]$, the items of the first step are not introduced by specific item markers, but are signaled by typographic markers (":"), syntactic parallelism and repetition of the lexical marker "soit" (or). The items of the second step are introduced by adverbial phrases including the "anaphoric correlates" "le premier" (the first), and "le second" (the second), analyzed in Schnedecker (2006) as a kind of multi-topic discourse. As a result, the anaphoric link is supported by a more complex referring mechanism involving co-items and anaphoric correlates.

[13] (a) Les organisations de salariés doivent choisir entre deux options stratégiques: (b) soit se laisser intégrer dans les pactes nationaux pour la compétitivité, (c) soit tenter de s'en dégager. (d) Dans le premier cas, (e) elles ne défendront les salariés que (f) dans la mesure où cette compétitivité de l'économie nationale le permettra [...]. (g) Dans le second cas, (h) elles peuvent tenter de retrouver leur capacité de mobilisation et (i) se reconstituer en tant que force d'opposition.

(a) Workers' organizations have to choose between two strategic options: (b) either enter into national agreements for reasons of competitiveness, (c) or attempt to escape from them. (d) In the first case, (e) they will only protect workers (f) when the competitiveness of the national economy allows it [...]. (g) In the second case, (b) they can try to recover their capacity to mobilize the workforce (i) and establish themselves as a force of opposition.

(Schnedecker, 2006: 307; we translate into English)

In this example, the second step describes the consequences of the two choices stated in the first step. In the following section, we explain why these examples challenge a strict view of RFC. 


\section{Two-step enumerative structures challenge RFC}

A naive treatment of the examples introduced above runs into trouble as soon as the attachment of the second step of the enumerative structure is considered. Intuitively, the first step of these enumerative structures leads to a hierarchical structure in which the trigger dominates the co-items. The co-items themselves are situated at the same level of discourse organization (see Figure 3). In [2], they even form a narrative sequence, as we will see in Section 6. Therefore, according to RFC, the co-items cannot be on the Right Frontier simultaneously. The trigger constituent ( $\pi_{\mathrm{a}}$ on Figure 3 ), the complex constituent containing the enumeration ( $\pi$ on Figure 3$)$ and the constituent containing the last item $\left(\pi_{c}\right.$ on Figure 3 ) are on the Right Frontier. On the other hand, the constituent containing the first item is not on the Right Frontier ( $\pi_{b}$ on Figure 3 ). Unfortunately, the co-items have been described as being both available for further development. These two-step enumerative structures seem to be similar to the interleaved structures mentioned in Asher (1993: 343).

\subsection{Discourse subordination}

For Asher, interleaved structures such as [I] constitute a case for the so-called discourse subordination mechanism. In this treatment, proper nouns ${ }^{4}$ are considered to be able to cross the Right Frontier in order to update the corresponding closed-off constituent with additional information. This treatment has the property to explain continuations such as [14], indicating that there is some kind of discourse object available for talking about all the information concerning each house.

[I] There are two houses you might be interested in: House A is in Palo Alto, House B in Portola Valley. Both were built in 1950, and both have 3 bedrooms. House A has 2 baths, and B, 4. House A also has a kidney-shaped pool. House A is on a quarter acre, with a lovely garden, while House B is on 4 acres of steep wooded slope, with a view of the mountains. The owner of House $B$ is asking $\$ 425 \mathrm{~K}$. The owner of house $\mathrm{A}$ is asking $\$ 600 \mathrm{~K}$.

[I4] That's all I know about House A, but I will know more about House B tomorrow.

This solution takes the objects described (here the houses) as the organizing principle. Therefore it promotes them as discourse topics guiding the overall discourse construction. Tackling this in terms of discourse structure leads to a complicated mechanism that violates the RFC and is not supported by any requirement from discourse processing (e.g., anaphora resolution). Moreover, discourse subordination was introduced in Asher (1993) but not taken up in Asher and Lascarides (2003), leaving the treatment of interleaved structures in SDRT as an open question.

4. However, Example [I] could be reworded with definites. 


\subsection{Topic creation}

Concerning anaphoric accessibility, the systematic use of specific referring tools such as definite descriptions, anaphoric correlates or repetitions of frame introducers considerably blurs the RFC picture. All these elements give instructions to pick up information that is somehow buried under more recent elements. The solution proposed in Asher (2008) to handle this issue is to treat definites as triggering the creation of a topic for the corresponding discourse entity. Danlos (2008) goes a step further and considers that definites can access any discourse referent in the left context. In our examples, such a topic is also easily identified and even suggested by the frame introducers for Example [2]. A direction we follow in the coming sections consists in looking at the available discourse attachment points for discourse continuations.

\section{A proposal for two-step enumerative structures}

\subsection{Treatment of the first step}

We analyze the first step of two-step enumerative structures, which is a classical enumerative structure, along the lines of the proposals presented in Section 2. We illustrate this analysis by constructing the SDRS for segments (a) to (g) of Example $[2]^{5}$.

- The co-item (b-d) introduces an intermediate level which is attached to the trigger constituent $\left(\pi_{\mathrm{a}}\right)$ by the Enumeration relation (see "Axiom Infer_Enumeration”).

- The second co-item (e-g) is also attached to the trigger $\left(\pi_{\mathrm{a}}\right)$ by the Enumeration relation and a coordinating relation (by default Continuation) is inferred between the co-items $\left(\pi_{\mathrm{b}-\mathrm{d}}\right)$ and $\left(\pi_{\mathrm{e}-\mathrm{g}}\right)$, see "Axiom Infer_Enumeration_OIM".

- In addition to the textual relation of Enumeration, the content-level relation of Elaboration is also inferred between $\left(\pi_{\mathrm{a}}\right)$ and $\left(\pi_{\mathrm{b}-c}\right)$ on the one hand and between $\left(\pi_{\mathrm{a}}\right)$ and $\left(\pi_{\mathrm{e}-\mathrm{g}}\right)$ on the other hand, since the two different events introduced in the trigger $\left(\pi_{\mathrm{a}}\right)$ are specified in the enumeration $\left(\pi_{\mathrm{b}-\mathrm{g}}\right)$ (elaboration of the two times). More generally, any subordinating relation may be found in this position. For instance, several elements of an Explanation can be organized as an enumeration (Vergez-Couret et al., 20II).

5. For practical and pedagogical reasons, when presenting this SDRT analysis, we do not respect the right order. Normally, each segment has to be integrated in the structure following the linear order of segments. 
- In Example [2], in addition to Continuation, we infer a more informative relation, Narration, between the co-items of the first step thanks to (i) the presence of two different spatial localizations including two different events and (ii) the temporal interpretation of the trigger "Deux fois" (twice or two times) that allows the lexical markers ("d'abord", first; "ensuite", then) to take a temporal value.

The construction obtained at this stage is given in Figure 4.

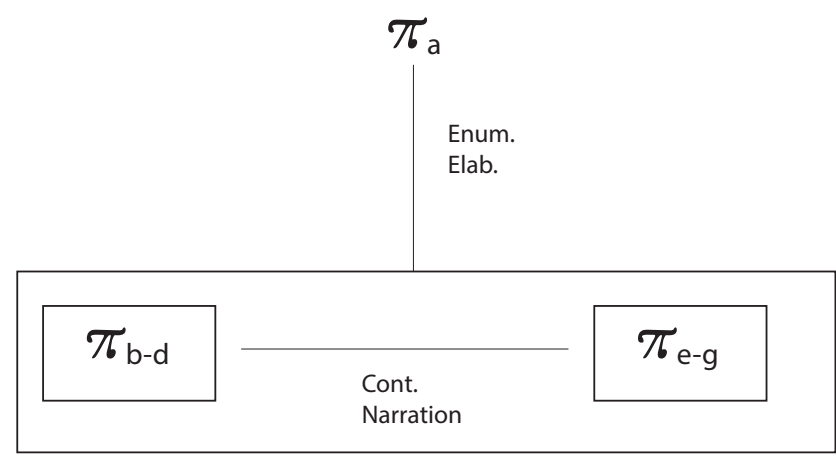

Figure 4. Discourse structure for segments (a-g) of Example [2]

Let us see now the structure inside the co-items.

- As mentioned in Section 2, we share with Vieu et al. (2005) the view that the frame introducers (b) and (e) introduce a new topic, here, what bappens at Vrin for $\left(\pi_{\mathrm{b}}\right)$ and what happens at the Beaubourg library for $\left(\pi_{\mathrm{e}}\right)$, which dominates a block of sentences through the Elaboration subordinating relation.

- Aspectual information (state-event alternation) together with the temporal marker "quand" (when) lead us to infer the background-foreground structure between $\left(\pi_{c}\right)$ and $\left(\pi_{d}\right)$ on the one hand and between $\left(\pi_{\mathrm{f}}\right)$ and $\left(\pi_{\mathrm{g}}\right)$ on the other hand. In this case, Asher et al. (2008) proposed to introduce a complex structure with an additional framing topic constituent, here satisfied by the content of the frame introducers, respectively $\left(\pi_{\mathrm{b}}\right)$ and $\left(\pi_{\mathrm{e}}\right)$, linked to the background by a Background relation (respectively Background $\left(\pi_{b}, \pi_{c}\right)$ and Background $\left(\pi_{e}, \pi_{f}\right)$ ) and to the foreground by an Elaboration (respectively Elaboration $\left(\pi_{b}, \pi_{d}\right)$ and Elaboration $\left.\left(\pi_{e}, \pi_{f}\right)\right)$.

- And finally, Parallel is inferred on the basis of syntactic parallelism between the two complex constituents $\left(\pi_{\mathrm{b}-\mathrm{c}}\right)$ and $\left(\pi_{\mathrm{e}-\mathrm{g}}\right)$.

The discourse structure for the first step (i.e., the classical enumerative structure) of [2] is given in Figure 5. 


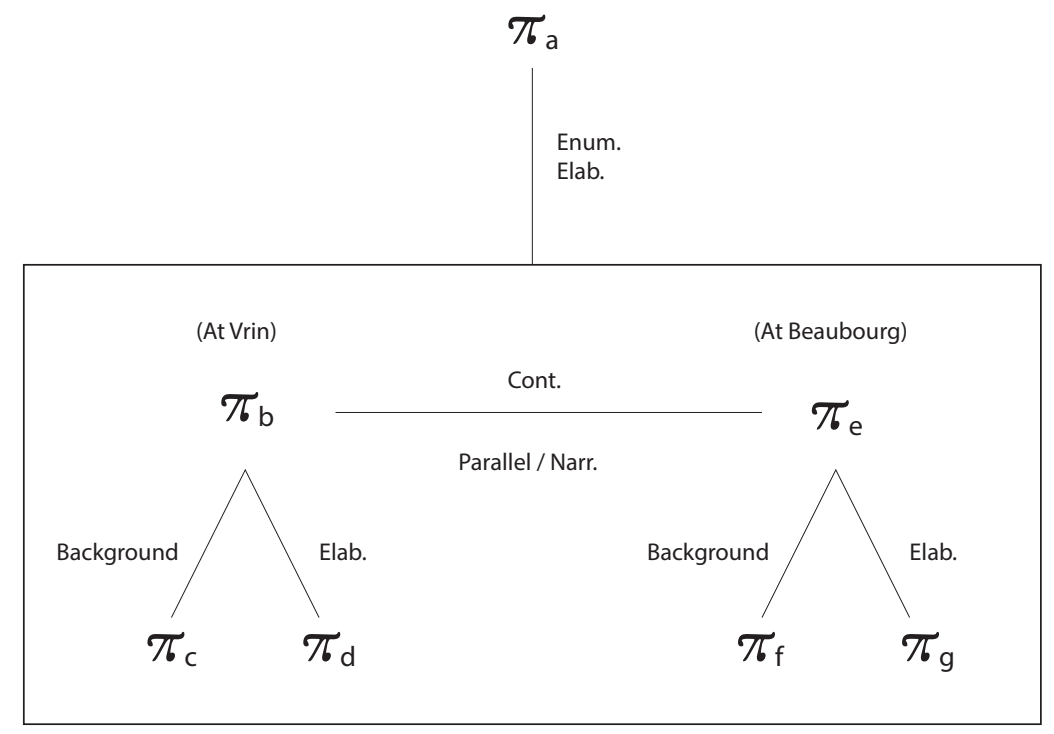

Figure 5. Structure for the first step of Example [2]

\subsection{Treatment of the second step}

We now want to extend the proposal to account for two-step enumerative structures. When representing the second step, we consider the attachment of elements by successively developing the co-items. There are two ways to approach such examples. The first one uses discourse subordination and was described briefly in the Section 4.I. The second option consists in following the surface level more straightforwardly and in considering that the deep semantic structure is somehow secondary here and can be retrieved from semantic interpretation without a direct counterpart at the structural level.

This is the solution we have chosen for two-step enumerative structures. From a cognitive viewpoint, it seems to us that the two-step enumerative structure is more salient than the spatiotemporal structure of the story which comes only subsequently to the interpreter's mind. This was confirmed several times by using this example as class material. Most of the students first detected the textual organization (i.e., the two-step enumerative structure) and then, while reading a second time, mentioned the spatiotemporal structure.

We prefer therefore to give precedence to the information given by the two-step enumerative structure and take it as guiding the interpretation of the discourse structure. Our proposition consists in attaching the two co-items of the second step (h-l) and (m-o) directly to the constituent corresponding to the trigger $\left(\pi_{\mathrm{a}}\right)$, as we did for the co-items of the first step, with an Enumeration relation. As a result, the trigger constituent $\left(\pi_{\mathrm{a}}\right)$ becomes the main topic of the overall two-step enumerative structure and also plays the role of topic for $\left(\pi_{\mathrm{b}}\right)$ and $\left(\pi_{\mathrm{e}}\right)$ on the one hand and $\left(\pi_{\mathrm{h}}\right)$ and $\left(\pi_{\mathrm{m}}\right)$ on the other hand (see Figure 5$)$. This option is supported 
by singular anaphoric resolutions that do not seem to be allowed across co-items of the different steps, but that are allowed with plural anaphora as in [I5].

[I5] At Vrin, Nil was afraid that the two lovers might have noticed his weird behavior.

This solution is a more conservative and standard treatment of the role and nature of the RFC since there is no constituent crossing the Right Frontier (contrarily to the discourse subordination treatment).

The spatiotemporal structure will be tackled at the level of semantic interpretation, as we will see in Section 6.3. This approach is similar to the one proposed by Egg and Redeker (2008) and Danlos (2008) as discussed in Section 7.

For now, we illustrate this analysis by constructing the SDRS for segments (h-o) of Example [2] ${ }^{6}$.

- The two co-items $(\mathrm{h}-\mathrm{l})$ and $(\mathrm{m}-\mathrm{o})$ are attached to the trigger constituent $\left(\boldsymbol{\pi}_{\mathrm{a}}\right)$ by Enumeration, guided by the symmetry between the two steps.

- An Elaboration is also inferred between $\left(\pi_{\mathrm{a}}\right)$ and $\left(\pi_{\mathrm{h}-1}\right)$ on the one hand and $\left(\pi_{\mathrm{a}}\right)$ and $\left(\pi_{\mathrm{m}-\mathrm{o}}\right)$ on the other hand on the basis of the semantic content of $\pi_{a}$ : "crut sombrer dans le gouffre" (thought that he was in big trouble). A two-step development is hinted at: (i) why Nil thought that he was in big trouble; and (ii) why he only thought that he was but was not in the end.

The structure inside the co-items is as follows:

- Frame introducers $(\mathrm{h})$ and $(\mathrm{m})$ introduce a new topic (what bappens at Vrin for $\left(\pi_{\mathrm{h}}\right)$ and what happens at the Beaubourg library for $\left.\left(\pi_{\mathrm{m}}\right)\right)$, which dominates a block of sentences through the Elaboration subordinating relation.

- The conjunction "dès que" (as soon as) triggers Narration between $\left(\pi_{\mathrm{i}}\right)$ and $\left(\pi_{\mathrm{j}}\right)$.

- A combination of lexical semantics and world knowledge allows the interpreter to identify an Occasion link between "se jeter" (escape) in ( $\mathrm{j})$ and "sortir" (reappear) (k). Narration is then inferred between $\left(\pi_{\mathrm{j}}\right)$ and $\left(\pi_{\mathrm{k}}\right)$.

- The lexical marker "après" (after) in (l) gives the instruction to interpret (l) as a flashback to (k). Flasbback is then inferred between $\left(\pi_{\mathrm{k}}\right)$ and $\left(\pi_{1}\right)$.

- (n) gives background to the segment (o). The framing topic constituent is satisfied by the content of the frame introducer $\left(\pi_{\mathrm{m}}\right)$ and linked to the background $\left(\pi_{\mathrm{n}}\right)$ by a Background relation and to the foreground $\left(\pi_{0}\right)$ by an Elaboration relation, as for segments $(\mathrm{c}-\mathrm{d})$ and $(\mathrm{f}-\mathrm{g})$.

- And finally, a Parallel relation is inferred between complex segments $\left(\pi_{\mathrm{b}-\mathrm{g}}\right)$ and $\left(\pi_{\mathrm{h}-1}\right)$, on the basis of structural parallelism inside the complex constituents.

6. As for the analysis of the first step of [2] and for the same reason, the right order of integration of new constituents in the SDRS is not respected here. 


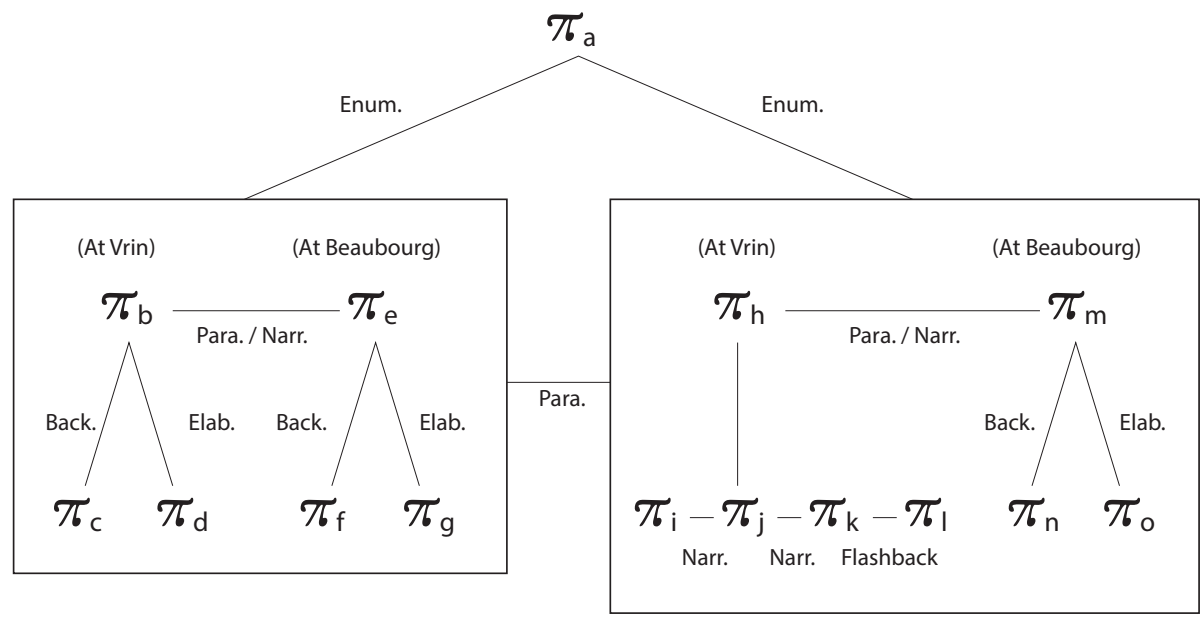

Figure 6. Structure for Example [2]

At the current stage of our work, we do not have any exhaustive inventory of the cues that signal a second step, so it is too early to provide any axioms to constrain the construction of the discourse structure once the two-step nature of the structure has been identified. That is why we only give the discourse structure we wish to obtain. In fact, identifying a second step is not straightforward. First, having a classical enumerative structure and identifying a potential second step is not sufficient to predict that the second step will have the same discourse organization as the first step. Therefore we cannot state constraints in this direction, even once a first item marker has been recognized in the second step. Secondly, we have not studied in detail second step item markers. Only a few of them seem to constrain the structure enough in order to provide construction rules. More precisely, as far as second step item markers are concerned, following Schnedecker (2006), it is impossible to have "l'un" without "l'autre" but, for example, "le premier" may appear without "le second". Therefore it seems that the principles guiding the interpretation of two-step enumerative structures come from the individual item marker semantics rather than from a general organizing rule of enumerative structures.

At this stage of our study, it is the compositional semantic contribution of all these different item markers (such as lexical item markers or frame introducers in Example [2]) that makes it possible to build up the structure, not rules coming from higher-level structures. These markers exhibit an interesting variety concerning the way they single out information that will be used to understand the discourse structure. This is also why we cannot treat here all the cases (for Example [I]). We believe that the referring devices used influence the nature of the reference links and the overall structure. 
Another element is the tenuous but important semantic contribution of the introducing sentence. A closer look at this sentence signals some subtleties about the elements being developed in the enumerative structure. For instance in [2], a careful reader might expect a two-step development of the introducing sentence: (i) why Nil thought that he was in big trouble; and (ii) why he only thought that he was but was not in the end. It seems that such sentences announcing a two-step event signal a coordination relation between the two steps. However, this two-step announcement relies on very tenuous clues, difficult to take into account in a systematic way.

\section{A solution for inferring deep semantic structure}

The preceding section argued for a discourse structure grounded on textual organization for examples like [2]. Nevertheless, the semantic structure of such examples plays a role and should not be left aside. We propose to combine the contribution of surface-based cohesion devices and deep semantics to account for the overall coherence of interleaved structures. To do so, we need to analyze their spatiotemporal semantics or more generally their semantic structure (alternative/ consequence relations in [13], spatiotemporal relationships in [2]). In both cases, the second step of each co-item has to be related with its "original" item. This is inferred on the ground of (i) the unambiguous identification of the item concerned by the development (for example, by proper noun designation like At Vrin, At Beaubourg), (ii) the Parallel relation inferred between the complex constituents corresponding to the different steps of the enumerative structure.

\subsection{Topic content}

Our solution relies on the semantic content of the topic that dominates the whole two-step enumerative structure. This topic should include the plural entity discourse referent described by the trigger and referents corresponding to the participants and objects involved in this plural entity, these referents being described by the co-items of the enumeration. Moreover these referents have to be organized according to the potential discourse adverbials they are associated with. Such a structure allows for reference through sophisticated means such as anaphoric correlates, presented above. These structured topics also explain the semantic grouping of the different bits of information under a given topic. This suggests that all the information concerning one topic is retrieved rather easily. On the other hand, we propose that such semantic content does not directly correspond to the coherence structure of the text which is provided in general by more explicit structuring clues.

\subsection{The semantic contribution of the second step co-item markers}

We now go back to the identification of the second step of enumerative structures. As we have just explained above, the plural entity of the trigger is developed into its different constituting elements. They correspond to the co-items and are apparently available, at least for definite reference. However, they are both equally accessible, 
which leads to an ambiguity. The semantic contribution of the second step co-item markers is therefore crucial.

They allow unambiguous identification of the elements developed in the second step. This ambiguity can be resolved either:

- by using adjectives such as "le premier" (first), "le second" (second) as illustrated in Example [13];

- by repetitions of frame introducers, as in Example [2];

- or by proper nouns designation (similarly to Example [r]).

The first case was studied in Schnedecker (2006). She distinguishes between "l'un/l'autre", opaque anaphoric correlates, that are potentially ambiguous and "le premier/le second", identifying anaphoric correlates, which resolve the ambiguity. In order to tackle these subtleties, the topic must include some information about the order in which the elements that constitute the topic have been introduced in the discourse. Anaphoric correlates like "le premier" require an ordered set (a kind of list) in which the anaphoric correlate will pick the first element. It introduces a further constraint on the attachment of the discourse segment. The attachment point must include such a list in its semantic content. The solution lies therefore in a sophisticated content for the discourse topic (see previous section) and in the semantics of each anaphoric correlate.

In the second case, the frame introducer rule can be applied (Vieu et al., 2005) and results in the addition of a specific semi-explicit constituent. Semi-explicit constituents are associated to a linguistic form like explicit constituents but they are strongly underspecified. They have to be updated, in the case of frame introducers, with the content of the constituents under the scope of the frame introducers.

The only satisfactory attachment point available for the frame introducer is the trigger since the corresponding more specific item - suggested by the repetition - is not situated on the Right Frontier.

Finally, we leave out the third case for now as it requires a complete treatment of definites which is beyond the scope of this paper. However, we believe that there should be some intermediate solution between the strong constraints on definite constructions proposed in Asher (2008) and the no-constraint solution about definites proposed in Danlos (2008) (see Section 3.2).

\subsection{Inferring deep semantic structure}

We illustrate how deep semantic structure is retrieved from the discourse structure with the analysis of the spatiotemporal information in [2].

Concerning semantic representation and interpretation, we follow Vieu et al. (2005) and Asher (2008) by postulating a semi-explicit constituent for each co-item frame introducer that needs to be created and updated. In Example [2], 
it is a spatial frame introducer. Following the same proposal, this constituent has the following content: $\exists e \exists P P(e) \wedge \emptyset(e)$. In this formula, $P$ corresponds to the predicate describing the eventuality concerned by the frame and $\emptyset$ corresponds to the information brought by the frame and has for Example [2] a spatial nature. This proposition is instantiated for Example [2]-(b) with $\exists e_{b} \exists P P\left(e_{b}\right) \wedge \operatorname{chezVrin}\left(e_{b}\right)$, where $P$ can be considered to be a generalization of what happened further localized by "chez Vrin", as described in the first step. Similarly, to the second step will correspond a constituent $\exists e_{b} \exists P P\left(e_{b}\right) \wedge \operatorname{chezVrin}\left(e_{b}\right)$.

This information has then to be exploited in order to infer the exact temporal structure. More precisely, the interpretation of Example [2] runs as in the following.

(a): The temporal adverbial "Deux fois" is a frame introducer: as seen above, it introduces a semi-explicit constituent including an underspecified eventuality. Here a composite eventuality $\mathrm{e}_{\mathrm{a}}$ composed of two underspecified sub-events:

$$
\begin{aligned}
& \mathrm{e}_{\mathrm{r}} C_{\mathrm{t}} \mathrm{e}_{\mathrm{a}} \\
& \mathrm{e}_{2} C_{\mathrm{t}} \mathrm{e}_{\mathrm{a}}{ }^{7}
\end{aligned}
$$

Moreover this composite eventuality $\mathrm{e}_{\mathrm{a}}$ is partially specified by "crut sombrer dans le gouffre" (thought that he was in big trouble) that announces the two steps of each event $\left(e_{1}\right.$ and $\left.e_{2}\right)$ as explained in Section 5.2.

(b): As explained above, framing adverbials introduce underspecified events. However, as explained in Asher (2008), in order to avoid a profusion of unnecessary representation levels we look for already introduced eventualities and check whether they correspond to the eventuality newly introduced. Here, $e_{1}$ and $e_{2}$ are already underspecified events waiting to be specified. Therefore, we get:

$$
e_{b}=e_{1}
$$

However the Vrin story is developed in two steps: the step developed under $\left(\pi_{\mathrm{b}}\right)$ and the one developed under $\left(\pi_{\mathrm{h}}\right)$. The relation between these eventualities is therefore:

$$
\mathrm{e}_{\mathrm{b}} \sqcup \mathrm{e}_{\mathrm{h}}=\mathrm{e}_{\mathrm{r}}{ }^{8}
$$

$(\mathrm{c}-\mathrm{d})$ : The discourse structure for $\left(\pi_{\mathrm{b}}\right),\left(\pi_{\mathrm{c}}\right)$ and $\left(\pi_{\mathrm{d}}\right)$ leads to the following temporal relations:

$$
\mathrm{sc}_{\mathrm{c}} \mathrm{O}_{\mathrm{t}} \mathrm{e}_{\mathrm{d}}
$$

and, by temporal reasoning:

$\mathrm{s}_{\mathrm{c}} C_{\mathrm{t}} \mathrm{e}_{\mathrm{b}}$ and $\mathrm{e}_{\mathrm{d}} C_{\mathrm{t}} \mathrm{e}_{\mathrm{b}}$

7. $c_{\mathrm{t}} ;<\mathrm{t} ; \mathrm{O}_{\mathrm{t}}$ respectively stand for temporal inclusion, temporal precedence and temporal overlap.

8. $\sqcup$ means that the contents of $e_{b}$ and eg together constitute the content of $e_{\mathrm{I}}$. 
(e): Similarly to (b), we get $e_{e}=e_{2}$. The inference of Narration between the two constituents $\left(\pi_{\mathrm{b}}\right)$ and $\left(\pi_{\mathrm{e}}\right)$ results at the semantic level in the following temporal relations:

$\mathrm{e}_{\mathrm{b}}<\mathrm{C}_{\mathrm{t}} \mathrm{e}_{\mathrm{e}}$

(f-g): Consistently with $\left(\pi_{c-d}\right)$, we get:

$s_{f} O_{t} e_{g}, s_{f} C_{t} e_{e}$ and $e_{g} C_{t} e_{e}$

(h): The new frame introducer matches with the previous one in (b), eb and $\mathrm{e}_{\mathrm{h}}$ correspond to the same spatial frame. This helps us to consider the temporal relations between sub-eventualities described under $\left(\pi_{\mathrm{b}}\right)$ and under $\left(\pi_{\mathrm{h}}\right)$.

$(\mathrm{i}-\mathrm{j})$ : On one hand, Narration between $\left(\pi_{\mathrm{i}}\right)$ and $\left(\pi_{\mathrm{j}}\right)$ leads to:

$e_{i}<e_{j}$

On the other hand, two other clues point toward looking at potential links between $e_{i}$ and the preceding discourse: the coreference between $e_{h}$ and $e_{b}$, and the use of the pluperfect (French plus-que-parfait) instead of the preterit (French passé composé or passé simple). Pluperfect tense signals a specific temporal structure positioning the event $e_{i}$ sometime earlier than another event available. Moreover, a combination of lexical semantics and world knowledge leads us to infer a link similar to the one expressed by Occasion between the event types of Laure entered and Nil had seen Laure. Our position here is to take this link between eventualities into account only for deep spatiotemporal interpretation but not at the rhetorical level where the prominent organization is given by the spatial frames. In other words, we have sufficient semantic information to infer temporal ordering between (d) and (i), but the question of their attachment does not even arise because of the discourse construction rules. Therefore the Narration relation is not inferred here:

$e_{d}<t e_{i}$

$(\mathrm{k}-1)$ : Narration between $\left(\pi_{\mathrm{j}}\right)$ and $\left(\pi_{\mathrm{k}}\right)$ on one hand and Flasbback between $\left(\pi_{\mathrm{k}}\right)$ and $\left(\pi_{1}\right)$ on the other hand leads to:

$\mathrm{e}_{\mathrm{j}}<_{\mathrm{t}} \mathrm{e}_{\mathrm{l}}<_{\mathrm{t}} \mathrm{e}_{\mathrm{k}}$

(m): As for (b) and (h), we can identify the spatial frame for (e) and (m):

$\mathrm{e}_{\mathrm{e}}=\mathrm{e}_{2}$

$\mathrm{e}_{\mathrm{e}} \sqcup \mathrm{e}_{\mathrm{m}}=\mathrm{e}_{2}$

$(\mathrm{n}-\mathrm{o})$ : The discourse structure for $\left(\pi_{\mathrm{m}}\right),\left(\pi_{\mathrm{n}}\right)$ and $\left(\pi_{\mathrm{o}}\right)$ leads to the following temporal relation:

$\mathrm{S}_{\mathrm{n}} \mathrm{O}_{\mathrm{t}} \mathrm{e}_{\mathrm{o}}$

and, by temporal reasoning:

$\mathrm{s}_{\mathrm{n}} C_{\mathrm{t}} \mathrm{e}_{\mathrm{m}}$ and $\mathrm{e}_{\mathrm{o}} C_{\mathrm{t}} \mathrm{e}_{\mathrm{m}}$ 
Thanks to this inclusion, we check the potential temporal relationship with the other eventuality of the Beaubourg story. Here again, we get a kind of Occasion link between "Anne-Geneviève apparut" (Anne-Geneviève appeared) and "Anne-Geneviève n'était restée qu'un instant" (Anne-Geneviève only stayed for a second). Therefore we infer the corresponding temporal relation:

$$
e_{g}<t s_{n}
$$

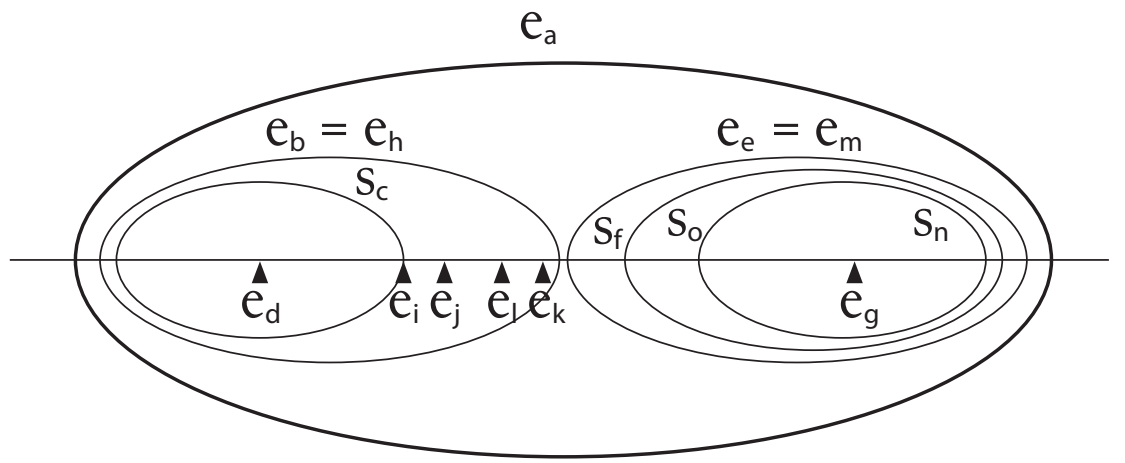

Figure 7. Temporal structure for [2]

\section{Related work on interleaved structures}

The example analyzed in the preceding sections constitutes a prototypical case of interleaved structures. In this case, the interleaved structure is generated by the possibility of inferring semantic relations and textual relations that do not appear to be isomorphic as can be seen in Figures 6 and 7 .

Wolf and Gibson observed the same phenomena in their annotation experiments (Wolf et al., 2003; Wolf \& Gibson, 2005). They attempted to bring together all the relations in discourse, i.e., relations given by surface level as well as relations given by deep semantic structure. However they would handle Example [2] in a rather different way. Contrarily to us, they do not consider that a frame introducer (e.g., "À Beaubourg”, At Beaubourg) constitutes a discourse segment. In their analysis, these frame introducers have to be part of the subsequent segment. Therefore, our proposal presents a richer hierarchical structure provided by the frame introducers. Another difference lies in the structural properties of discourse relations in the different frameworks. While SDRT's subordinating and coordinating relations impose constraints on the structure of the following discourse, Wolf and Gibson's structures do not impose such constraints. Therefore, while SDRT uses the tree-like structure induced by structural properties of relations for predicting purposes, Wolf and Gibson handle a more flexible graph-like structure without much predictive power. More precisely, for Example [2], Wolf and Gibson would 
propose a Temporal Sequence between (d) and (i), and between (g) and (n). According to them, such structures, called in their framework crossed dependencies, support the graph-like understanding of discourse structure (see Figure 8).

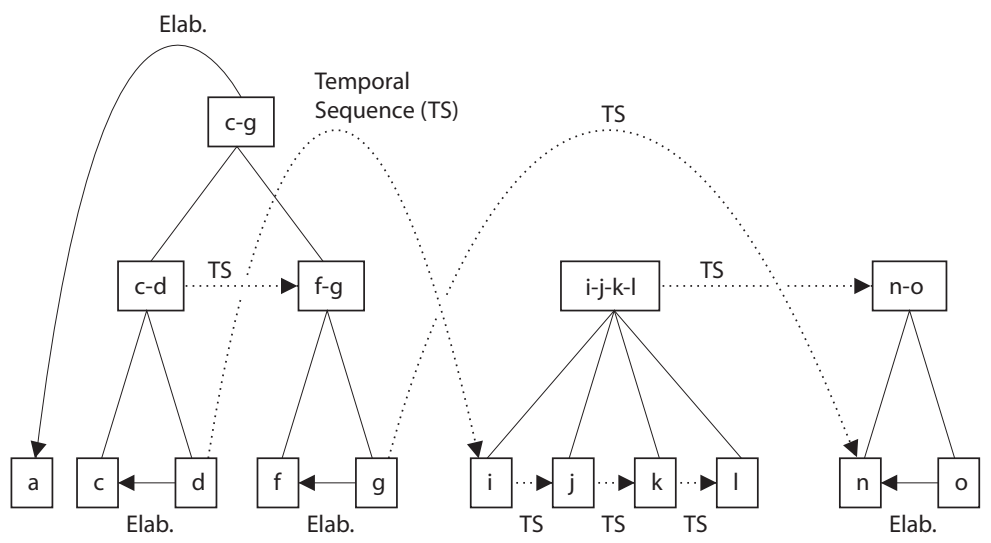

Figure 8. Crossed dependencies (Wolf \& Gibson, 2005)

Egg and Redeker (2008) disagreed with Wolf and Gibson's analysis because it fails to take explicit linguistic signals into account. According to them, such clues should have priority for establishing discourse structure. In Example [2], surface structure is given by the frame introducers that create a strong coherence and signal the Parallel relation. Egg and Redeker solve the interleaved structure issue by considering that when competing structures can be proposed, the one supported by explicit linguistic markers takes precedence. For our example, Egg and Redeker would somewhat disregard deep semantic structure. This view is endorsed by Danlos and Hankach's (2008) analysis. Their solution cannot represent anaphoric links between frame introducers "Chez Vrin" ((b) and (h)) and "À Beaubourg" ((e) and (m)). Indeed, according to them, "anaphoric links cannot systematically be represented in discourse structure" (Danlos \& Hankach, 2008: 29).

These contrasting analyses proceed from two different visions of discourse structure. Wolf and Gibson include in the same representation the structure given by surface level markers and the structure given by deep semantic structure. Danlos and Hankach, following Egg and Redeker, reflect only the surface level structure and argue that some anaphoric links cannot be represented in discourse structure. Our proposal takes advantage of the textual structure level and we retrieve deep semantic structure from the textual level in this case.

\section{Generalization}

Although satisfactory for examples like [2], the treatment proposed in Section 6.3 is slightly too specific to handle cases like [13]. Both examples include: 
- A plural discourse entity, called prospect NP: "Deux fois", "deux options". In both cases, developing the single entities forming this plural in a distributive way could lead to a relatively new kind of discourse structure. The nature of these discourse entities allows them to be developed distributively on the same footing, even with a coordinating relation (Narration in [2], Consequence in $\left[\mathrm{I}_{3}\right]$ ).

- Strong discourse clues (frame introducer repetitions, anaphoric correlates...) that signal, together with significant parallelism within the structure of the complex constituents, higher-level structures between complex constituents. The idea underlying the original discourse subordination surfaces here but we will attempt to tackle it in a more conservative way than the original discourse subordination proposal (Asher, 1993).

The idea is to look at what happens when complex constituents are related by content relations. In SDRT, complex constituents are more like information packages that do not play a direct role in semantic constraints. They are by-products of the structure created by semantic interpretation. Therefore, they are related to other constituents by dominance relationships (the labeled frames around the structures in our figure) or by structural relations. Here we would like to allow these complex constituents to enter as arguments of content relations. We propose that content relations between complex constituents can be verified through the satisfaction of the semantic constraints of the relation between the simple constituents forming the complex ones. More precisely, the constraints we propose are stated in Formula I.

\subsection{Constraints on discourse relations between complex constituents}

$R I(\alpha, \beta, \lambda) \wedge R I(\gamma, \delta, \mu) \wedge \operatorname{Parallel}(\lambda, \mu, \nu) \wedge\left(\varnothing R_{2}(\alpha, \gamma) \wedge \emptyset R_{2}(\beta, \delta)\right) \rightarrow R_{2}(\lambda, \mu, \nu)$

The application of this constraint to Example [2] yields the following results:

$\operatorname{Narration}\left(\pi_{b}, \pi_{e}, \pi_{A}\right) \wedge \operatorname{Narration}\left(\pi_{h}, \pi_{m}, \pi_{B}\right) \wedge \operatorname{Parallel}\left(\pi_{A}, \pi_{B}, 0\right) \wedge\left(\emptyset_{\text {Narration }}\left(\pi_{b}, \pi_{h}\right)\right.$ $\left.\wedge \emptyset_{\text {Narration }}\left(\pi_{e}, \pi_{m}\right)\right) \rightarrow \operatorname{Narration}\left(\pi_{A}, \pi_{B}, O\right)$

Let us now examine the discourse representation of Example [13] and the application of the constraint stated in Formula I to this example in Figure 9:

Alternative $\left(\pi_{b}, \pi_{c}, \pi_{A}\right) \wedge$ Alternative $\left(\pi_{d}, \pi_{g}, \pi_{B}\right) \wedge \operatorname{Parallel}\left(\pi_{A}, \pi_{B}, O\right) \wedge\left(\varnothing_{\text {Consequence }}\left(\pi_{b}, \pi_{c}\right)\right.$ $\left.\wedge \emptyset_{\text {Consequence }}\left(\pi_{c}, \pi_{g}\right)\right) \rightarrow$ Consequence $\left(\pi_{A}, \pi_{B}, O\right)$

As for the attachment of such structures to the trigger $\left(\pi_{a}\right)$, there is Enumeration/ Elaboration ${ }^{9}$ between the trigger and the first step of the enumerative structure. The second step $\left(\pi_{\mathrm{d}-\mathrm{i}}\right)$ is only attached by Enumeration ${ }^{10}$.

9. The notation $\mathrm{R}_{\mathrm{a}} / \mathrm{R}_{\mathrm{b}}$ was introduced in Danlos (2008) and means that both relations hold between the constituents.

10. It would be tempting to add the relation holding between the first step and the second step between the trigger and the second step. Indeed, as the first step is an elaboration of the specified trigger, the semantic function of these elements with respect to the second step is equivalent. 


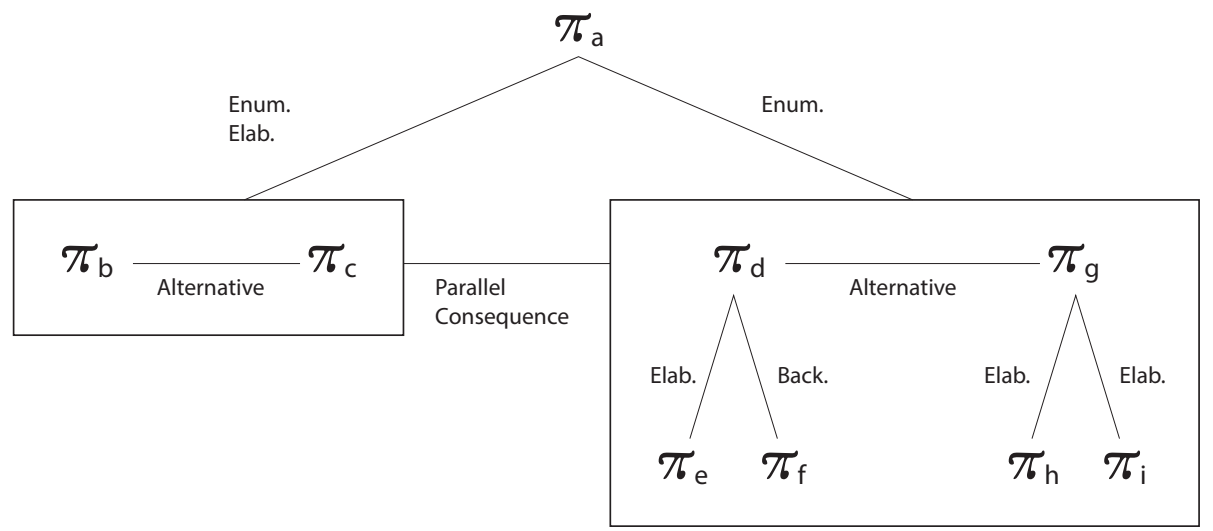

Figure 9. Structure for Example [13]

\section{Conclusion}

To sum up the benefits of our treatment: (i) it is a more conservative and standard treatment than the discourse subordination of Asher (1993) concerning the role and nature of RFC, for a topic that has not received much attention since this proposal, (ii) it takes up detailed empirical observations from Schnedecker (2006) which we consider to be essentially correct, and (iii) it offers a framework that can be extended to more general cases (e.g., frame accessibility without enumerative structures). Finally, by paying attention to enumerative structures that correspond more to a textual level, we hope to contribute to the study of the interaction between semantic and textual levels. More generally this kind of study constitutes a step toward a better understanding of the interaction between the different aspects of discourse structure. This issue is crucial if one attempts to use discourse structure as a source of constraints for a predictive model (such as the one needed for anaphora resolution). When different discourse levels, here deep semantic structure and textual structure, seem to shape discourse structure differently, one has to make a decision about how to use them. Interleaved structures constitute an interesting body of data for studying how deep semantic structure can replace surface-based cohesion to ensure discourse coherence, although this work only scratches the surface of the interaction between the different dimensions of discourse coherence. It provides some more theoretical background and the analysis of authentic examples for moving toward more global questions on this issue. It has often been considered that semantic structure constitutes the backbone of discourse structure; the example analyzed here, however, exhibits a case in which textual organization is stronger. We consider that it is the framing textual organization and not only the spatial nature of the frames that confers the structuring power of this construction. Further investigations are needed on framing segments such as "dans le premier cas" and "dans le second cas" which might be treated as information packaging constituents, i.e., constituents giving different kinds of instructions both at the textual level and at the content level. 
However only corpus-based or experimental studies may provide answers to this kind of question. Corpus study can provide quantitative information about these issues. Then annotation campaigns and experiments will reveal how interpreters process examples in which several discourse coherence dimensions compete. Several projects such as the Penn Discourse Treebank (Prasad et al., 2008) or the DISCOR project (Reese et al., 2007) on English Language, or the ANNODIS project (Afantenos et al., 20I2) on French Language, are attempting, among more applicative goals, to answer these issues.

\section{References}

Afantenos, S. et al. 20I2. An Empirical Resource for Discovering Cognitive Principles of Discourse Organisation: The ANNODIS Corpus. In Proceedings of the 8th International Conference on Language Resources and Evaluation (LREC 2OI2). Stroudsburg: Association for Computational Linguistics: 2727-2734. Available online: http://www.lrec-conf.org/ proceedings/lrec2oi2/pdf/836_Paper.pdf.

AsHeR, N. 1993. Reference to Abstract Objects in Discourse. Dordrecht - Boston - London: Kluwer Academic Publishers.

Asher, N. 2008. Troubles on the Right Frontier. In A. Benz \& P. KüHnLein (eds.), Constraints in Discourse. Amsterdam: J. Benjamins: 29-52.

Asher, N. \& LasCarides, A. 2003. Logics of Conversation. Cambridge: Cambridge University Press.

Asher, N. \& Moreau, M. 199i. Common Sense Entailment: A Modal Theory of Nonmonotonic Reasoning. In J. Mylopoulos \& R. Reiter (eds.), IJCAI-gr: Proceedings of the I2th International conference on artificial intelligence, Sydney, 24-30 August I99I. San Mateo: M. Kaufmann: 387-392.

Asher, N., Hardt, D. \& Busquets, J. 20oI. Discourse Parallelism, Ellipsis and Ambiguity. Journal of Semantics I8 (I): I-25.

Asher, N., Prévot, L. \& Vieu, L. 2007. Setting the Background in Discourse. Discours I. Available online: http://discours.revues.org/30I.

Aurnague, M. \& Vieu, L. 1993. A Three-Level Approach to the Semantics of Space. In C. Zelinski-Wibielt (ed.), The Semantics of Prepositions: From Mental Processing to Natural Language Processing. Berlin: Mouton de Gruyter: 393-439.

Bateman, J.A. \& Rondhuis, K.J. 1997. "Coherence Relations": Towards a General Specification. Discourse Processes 24 (I): 3-49.

Bras, M. 2007. French Adverb d'abord and Discourse Structure. In M. Aurnague, K. Korta \& J. Larrazabal (eds.), Language, Representation and Reasoning. Memorial Volume to Isabel Gómez Txurruka. Bilbao: Universidad del País Vasco: 77-ı2.

Bras, M. \& Asher, N. 1994. Le raisonnement non monotone dans la construction de la structure temporelle de textes en français. In Reconnaissance des formes et intelligence artificielle: $9^{e}$ congrès, Paris, II-I4 janvier 1994. Paris: AFCET. Vol. 2: 223-234. 
Bras, M., Prévot, L. \& Vergez-Couret, M. 2008. Quelle(s) relation(s) de discours pour les structures énumératives? In J. Durand, B. Habert \& B. Laks (eds.), Actes $d u$ congrès mondial de Linguistique française ( $C M L F$ 2008). Paris: Institut de linguistique française: 1945-1964. Available online: http://www.linguistiquefrancaise.org/articles/ cmlf/pdf/2008/oi/cmlfo8225.pdf.

Charolles, M. 2005. Framing Adverbials and Their Role in Discourse Cohesion: From Connection to Forward Labelling. In Papers of the Symposium on the Exploration and Modelling of Meaning (SEM-o5). Available online: http://w3.erss.univ-tlsez.fr/semo5/ proceedings-final/o2-Charolles.pdf.

Danlos, L. 2008. Strong Generative Capacity of RST, SDRT and Discourse Dependency DAGs. In A. Benz \& P. KüHnleIn (eds.), Constraints in Discourse. Amsterdam: J. Benjamins: 69-95.

Danlos, L. \& Hankach, P. 2008. Right Frontier Constraint for Discourses in NonCanonical Order. In A. Benz, P. KüHnlein \& M. Stede (eds.), Proceedings of the Workshop “Constraints in Discourse III". 27-36. Available online: http://www.constraintsin-discourse.org/cido8/CIDIII/cidproceedings.pdf.

Degand, L. 1998. On Classifying Connectives and Coherence Relations. In Proceedings of the Workshop "Discourse Relations and Discourse Markers". Stroudsburg: Association for Computational Linguistics: 29-35. Available online: http://aclweb.org/anthologynew/W/W98/W98-0305.pdf.

EgG, M. \& Redeker, G. 2008. Underspecified Discourse Representation. In A. BenZ \& P. Kühnlein (eds.), Constraints in Discourse. Amsterdam: J. Benjamins: II7-I38.

Ho-Dac, L.-M., Péry-Woodley, M.-P. \& TAnguy, L. 20IO. Anatomie des structures énumératives. In Actes de la $I 7^{e}$ conférence sur le Traitement automatique des langues naturelles (TALN 2010 - Montréal, I9-23 juillet 20IO). Available online: http://www. iro.umontreal.ca/ffelipe/TALN2oro/Xml/Papers/all/taln2oı_submission_26.pdf.

Ho-Dac, L.-M. et al. 20I2. An Empirical Approach to the Signalling of Enumerative Structures. Discours Io. Available online: http://discours.revues.org/86II.

Kamp, H. \& Rohrer, C. 1983. Tense in Texts. In R. BäUerle, C. Schwarze, A. von Stechow (eds.), Meaning, Use and Interpretation of Language. Berlin - New York: W. de Gruyter: $250-269$.

Kamp, H. \& Reyle, U. 1993. From Discourse to Logic: Introduction to Modeltheoretic Semantics of Natural Language, Formal Logic and Discourse Representation Theory. Dordrecht - Boston - London: Kluwer Academic Publishers.

Knott, A., Sanders, T. \& Oberlander, J. 2002. Levels of Representation in Discourse Relations. Cognitive Linguistics I2 (3): 197-209.

Luc, C. et al. 1999. A Linguistic Approach to some Parameters of Layout: A Study of Enumerations. In R. Power \& D. ScotT (eds.), AAAI Fall Symposium Technical Report "Using Layout for the Generation, Understanding or Retrieval of documents". 35-45. Available online: http://www.aaai.org/Papers/Symposia/Fall/r999/FS-99-04/FS99-04-005.pdf.

Luc, C. et al. 200o. Les enumérations: structures visuelles, syntaxiques et rhétoriques. In M. Gaio \& É. Trupin (eds.), Document électronique dynamique: actes du troisième colloque international sur le document électronique (4-6 juillet 2000, Lyon). Paris: Europia: 21-40. 
Mann, W.C. \& Thompson, S.A. 1987. Rhetorical Structure Theory: A Theory of Text Organization. Technical report ISI/RS-87-I90. Los Angeles: University of Southern California, Information Sciences Institute. 92 p. Available online: http://www.sfu.ca/ rst/pdfs/Mann_Thompson_I987.pdf.

Polanyi, L. 1988. A Formal Model of the Structure of Discourse. Journal of Pragmatics I2 (5-6): 6oI-638.

Porhiel, S. 2007. Les structures énumératives à deux temps. Revue romane 42 (I): 103-135.

Prasad, R. et al. 2008. The Penn Discourse Treebank 2.o. In Proceedings of the 6th International Conference on Language Resources and Evaluation (LREC 2008). Stroudsburg: Association for Computational Linguistics: 296I-2968. Available online: http://www.lrec-conf.org/ proceedings/lrec2008/pdf/754_paper.pdf.

PRÉVOT, L. 2004. Structures sémantiques et pragmatiques pour la modélisation de la cohérence dans des dialogues finalisés. Unpublished $\mathrm{PhD}$ thesis. Université de Toulouse III.

REESE, B. et al. 2007. Reference Manual for the Analysis and Annotation of Rhetorical Structure (Version I.o). Technical report. Austin: University of Texas, Departments of Linguistics and Philosophy. Available online: http://timeml.org/jamesp/annotation_manual.pdf.

SAnders, T.J.M., Spooren, W.P.M. \& Noordman, L.G.M. 1992. Toward a Taxonomy of Coherence Relations. Discourse Processes I5 (I): I-35.

SCHNEDECKER, C. 2006. De l'un à l'autre et réciproquement... Aspects sémantiques, discursifs et cognitifs des pronoms anaphoriques corrélés l'un/l'autre et le premier/le second. Bruxelles: De Boeck-Duculot.

Vergez-Couret, M. et al. 2oII. Discourse Contribution of Enumerative Structures Involving pour deux raisons. In Proceedings of the Workshop "Constraints in Discourse IV". Available online: http://passage.inria.fr/cid2orI/lib/exe/fetch.php/cid2oII_submission_25.pdf.

VIEU, L. et al. 2005. Locating Adverbials in Discourse. Journal of French Language Studies I5 (2): 173-193.

Wolf, F. et al. 2003. A Procedure for Collecting a Database of Texts Annotated with Coherence Relations. Technical report. Cambridge: Massachusetts Institute of Technology, Department of Brain and Cognitive Sciences. Available online: http://www.ldc.upenn.edu/Catalog/ docs/LDC2005To8/database-documentation.pdf.

Wolf, F. \& Gibson, E. 2005. Representing Discourse Coherence: A Corpus-Based Study. Computational Linguistics 3I (2): 249-287. 